Rare structural variants found in attention-deficit hyperactivity disorder are preferentially associated with neurodevelopmental genes

\author{
J Elia, X Gai, HM Xie, JC Perin, E Geiger, JT Glessner, M D’arcy, R deBerardinis, E Frackelton, \\ C Kim, F Lantieri, BM Muganga, L Wang, T Takeda, EF Rappaport, SFA Grant, W Berrettini, \\ $\mathrm{M}$ Devoto, TH Shaikh, H Hakonarson and PS White
}

Molecular Psychiatry (2010) 15, 1122; doi:10.1038/mp.2010.75; published online 14 September 2010

Correction to: Molecular Psychiatry (2010) 15: 637-646; published online 23 June 2009; doi:10.1038/mp.2009.57

After publication of the article online, the authors wished to add the following statement to the Acknowledgement section:

We credit artist Colleen Gaynor for the artwork associated with this manuscript that is displayed on the cover of this issue.

The full Acknowledgement appears below:

The Children's Hospital of Philadelphia Institutional Review Board has approved this study. This work was supported in part by National Institutes of Health Grants K23MH066275 (JE), GM081519 (THS), and P30HD026979 (MD and XG); University of Pennsylvania Grant UL1-RR-024134 (JE); Pennsylvania Department of Health Grant SAP 4100037707 (PSW); and a Developmental Research Award from the Cotswold Foundation (SG and $\mathrm{HH}$ ). All genome-wide genotyping was funded by an Institutional Development Award from the Children's Hospital of Philadelphia $(\mathrm{HH})$. We thank all the participating individuals and families for making this study possible. We credit artist Colleen Gaynor for the artwork associated with this manuscript that is displayed on the cover of this issue.

\title{
Targeted disruption of serine racemase affects glutamatergic neurotransmission and behavior
}

\author{
AC Basu, GE Tsai, C-L Ma, JT Ehmsen, AK Mustafa, L Han, ZI Jiang, MA Benneyworth, \\ MP Froimowitz, N Lange, SH Snyder, R Bergeron and JT Coyle
}

Molecular Psychiatry (2010) 15, 1122; doi:10.1038/mp.2010.84; published online 14 September 2010

Correction to: Molecular Psychiatry (2009) 14, 719-727; published online 9 December 2008; doi:10.1038/ mp.2008.130

After the above article was published, the authors noted that the terminology used in the above article may create confusion for some readers.
The substance of the clarification is as follows:

Throughout the article the term 'exon 1' was used to refer to the first coding exon of the serine racemase gene. It should be noted that the murine serine racemase gene includes two non-coding exons upstream of that which we have deleted. 